\title{
Comparison of two technological procedures to enrich peeled pears in halves with fructooligosaccharides for later canning as a new functional food
}

\author{
Inés González Hidalgo, María Teresa Gil Borrás, José María Ros García* \\ Department of Food Science \& Technology and Human Nutrition, Veterinary Faculty, University of Murcia, Campus de Espinardo, 30100 \\ Murcia, Spain
}

\section{A B S T R A C T}

\begin{abstract}
Osmotic treatment and vacuum impregnation have been tried as possible methods to put fructooligosaccharides (FOS) into pears, getting a new functional canned fruit. Vacuum impregnation changes the texture of pears, becoming those pears softer than not treated pears. This change was resolved adding calcium into the impregnation medium. FOS were able to enter into pears with the two treatments and keep stable their concentration during two months of storage period at ambient temperature $\left(22 \pm 2{ }^{\circ} \mathrm{C}\right)$ after canning. The best retention of FOS $(61 \%)$ was for the osmotic treatment. The concentration of FOS in the canned pears and the corresponding syrup was up to 14 times higher using the osmotic treatment than the vacuum infiltration. Furthermore, sensory properties of treated pears containing FOS after two months from canning were similar to sensory properties of not treated canned pears, since FOS do not contribute to the sweetness of the canned pears. These results indicated that canned pears rich in FOS have potential to be a new functional food that can be produced at industrial level.
\end{abstract}

Keywords: Canned pears; Fructooligosaccharides; Functional foods; Osmotic treatment; Vacuum impregnation; Syrup

\section{INTRODUCTION}

Fructooligosaccharides (FOS) are fructose oligomers and may be classified into two main groups, such as inulin with $\beta$ (2-1) linkages and levans with $\beta$ (2-6) linkages (Li et al., 2015). FOS were mainly identified as 1 -kestose, nystose, and $1^{\mathrm{F}}$-fructofuranosylnystose (Nobre et al., 2018; Hidaka et al., 1986; Bornet et al., 2002; Gibson, 2004; Kumar et al., 2018). Furthermore, FOS have a low sweetness intensity, are calorie free, are not cariogenic and decrease the levels of serum cholesterol, phospholipids and triglycerides (McKellar and Modler, 1989; Sugizaki and Naves, 2018). FOS have high stability, since the FOS retention in acidic foods ( $\mathrm{pH} 3.5$ ) treated at $95^{\circ} \mathrm{C}$ is higher than $95 \%$ (Vega and Zuniga-Hansen, 2015). Due to these properties and having in mind the current concern about a healthy diet, it is interesting to add FOS to food, obtaining then a prebiotic/functional food.

The addition of novel functional ingredients such as probiotics and prebiotics to different kind of food, such as bread (Korus et al., 2006; Frutos et al., 2008), cookies (Ayyappan et al., 2015) and fruit juices (Vidal Fonteles and Rodrigues, 2018) is still a recent development.

To manage to add these functional ingredients into a solid, in this case into a pear, it can be used the osmotic treatment for canned pears and the vacuum impregnation for pears to be canned. During the osmotic process (Torreggiani and Bertolo, 2001), there are two major simultaneous countercurrent flows due to water and the osmotic solute activity (Torreggiani and Bertolo, 2001; Rastogi et al., 2004), and in the infusion of phenolics into fruits and vegetables (Rózek et al., 2010). On the other hand, vacuum impregnation of a porous product consists of exchanging the internal gas or liquid occluded in open pores for an external liquid phase due to the action of hydrodynamic mechanism (Betoret et al., 2003). It has been applied to introduce vitamins in apples (Yanyun et al., 2005) and antibrowning agents into pears (PérezCabrera et al., 2011).

\footnotetext{
${ }^{*}$ Corresponding author:

José María Ros García, Department of Food Science \& Technology and Human Nutrition, Veterinary Faculty, University of Murcia, Campus de Espinardo, E-30100 Murcia, Spain. E-mail: jmros@um.es
} 
The objectives of this work were to compare the osmotic treatment and the vacuum impregnation as the treatments to obtain halves of peeled pears enriched with fructooligosaccharides, and to evaluate the stability of the fructooligosaccharides in the canned pears during two months of storage.

\section{MATERIALS AND METHODS}

\section{Materials}

Raw pears (Pyrus communis L., Blanquilla variety, $\mathrm{pH} 4$, $12{ }^{\circ}$ Brix) were purchased at a local supermarket and stored at $4^{\circ} \mathrm{C}$ until use. The day of the treatment, each fruit was hand peeled, cut into two halves and the seeds were removed. They were put for $15 \mathrm{~min}$ into a bath with citric acid and ascorbic acid, both acids at $1 \mathrm{~g} / 1$, to avoid browning process.

Citric acid and sucrose were of food degree. Pasteurized natural lemon juice (acidity 5.5\% anhydrous citric acid, $8.0^{\circ}$ Brix) was provided by Tana S.A. (Los Ramos, Murcia, Spain). FOS (Oligofructose from inulin) were provided by Orafti (Tienen, Belgium).

\section{Design of the treatments}

The so called osmotic treatment consist that fructooligosaccharides were initially in the syrup of the can and due to their absence in the pears, it is expected that fructooligosaccharides will enter in the pears until the equilibrium between pears and syrup is reached, while in the so called vacuum impregnation, the fructooligosaccharides are in an impregnation solution which by vacuum application will be introduced in the halves of the peeled pears, enriching them with the fructooligosaccharides. Later on, the pears are canned in syrup without fructooligosaccharides. Then, it is expected that fructooligosaccharides will exit from the pears to the syrup, until the equilibrium between pears and syrup is reached.

\section{Osmotic treatment of the canned pears}

For the osmotic treatment two different syrups were prepared. One of them contained $80 \% \mathrm{w} / \mathrm{w}$ of water, $20 \% \mathrm{w} / \mathrm{w}$ of sucrose, and $0.2 \% \mathrm{w} / \mathrm{w}$ of citric acid (E-330). The other one was prepared with $4.2 \% \mathrm{w} / \mathrm{w}$ of pasteurized natural lemon juice, $19.7 \% \mathrm{w} / \mathrm{w}$ of sucrose and $76.2 \% \mathrm{w} / \mathrm{w}$ of water. Final concentration of soluble solids in both syrups was $20^{\circ}$ Brix.

A number of six batches were prepared with six cans per batch $(n=6)$. The first one contained peeled pears in halves, syrup with citric acid as mentioned above and no FOS. The second one contained peeled pears in halves, syrup with citric acid as mentioned above and FOS $(9.1 \% \mathrm{w} / \mathrm{w})$.
The third one was prepared only mixing syrup with citric acid as mentioned above and FOS $(9.1 \%, \mathrm{w} / \mathrm{w})$. Batches number four, five and six were prepared like the first three but with lemon juice as acidifying agent, instead of citric acid, into the syrup as mentioned above. Cans were filled with peeled pears in halves (around six halves per can), being the drained weight between 250 and $270 \mathrm{~g}$. Then, cans were filled with the hot syrup containing the citric acid and FOS, if any, to the upper brim and finally they were closed and sterilized (procedure of canning as mentioned below for all the canned pears).

Canned pears were stored during two month at room temperature $\left(22 \pm 2^{\circ} \mathrm{C}\right)$ before their analysis, avoiding direct sunlight.

\section{Previous vacuum treatment with calcium}

For the impregnation of calcium by vacuum treatment of the still not canned half pears, previously, five different concentrations of calcium were tested to determine the best one for pear texture. Concentrations tested were 0 (control), 50, 100, 200 and $500 \mathrm{mg}$ of calcium/1 of impregnation medium. These concentrations of calcium were obtained adding $\mathrm{CaCl}_{2}$ into the water. The impregnation medium contained $\mathrm{CaCl}_{2}, 9.1 \%(\mathrm{w} / \mathrm{w})$ of FOS and citric acid as mentioned above. In each experiment the pears were placed in a metal vacuum camera, and when a vacuum of $70 \mathrm{mbars}$ was reached, then the impregnation medium (calcium, FOS and citric acid) was introduced through a breaking-vacuum valve until atmospheric pressure was restored. Each group of halves pears was weighed before and after vacuum impregnation. Then texture (see below) was measured in order to select the concentration of calcium that better preserves the texture of the pears to be canned.

\section{Vacuum treatment with calcium and FOS of the pears to be canned}

Once the best concentration of calcium was established according to texture preservation of the pear halves, the batch of pears was impregnated to be canned. The impregnation medium contained $\mathrm{CaCl}_{2}(200 \mathrm{mg}$ of calcium/l), 9.1\%(w/w) of FOS and citric acid as mentioned above, following the procedure of impregnation also mentioned above, and the procedure of canning as mentioned below for all the canned pears.

Canned pears were stored during two month at room temperature $\left(22 \pm 2^{\circ} \mathrm{C}\right)$, avoiding direct sunlight. Sampling for analysis was done at 3,20, 35 and 60 days of storage of the different batches.

\section{Processing and canning}

The format of the cans used was $0.5 \mathrm{~kg}$. The cans were filled (approx. $260 \mathrm{~g}$ ) with the treated pears (osmotic 
treatment or vacuum impregnation), adding the corresponding hot syrup $\left(95^{\circ} \mathrm{C}\right.$, approx. $\left.170 \mathrm{~g}\right)$ according to each different treatment as mentioned before. Then, the filled cans $\left(60^{\circ} \mathrm{C}\right)$ were closed in a manual metal-can seamer and quickly, they were sterilized by immersion in hot water $\left(95^{\circ} \mathrm{C}\right.$ for $\left.15 \mathrm{~min}\right)$. The cans were cooled by immersion in water $\left(15^{\circ} \mathrm{C}\right)$ at the exit of the sterilizer. Finally, the cans were dry with paper and stored at room temperature $\left(22 \pm 2^{\circ} \mathrm{C}\right)$ avoiding direct sunlight, untill sampling.

\section{Sugars analysis}

Sugars determination was carried out by High-Performance Liquid Chromatography (HPLC), using a CHO-682 column (30 cm x 7.8 mm; Transgenomic, San Jose, CA, USA) and refractive index detection. Pure sugars from Merck (Darmstad, Germany) were used as external standards for calibration. More details on sample preparation and HPLC analysis were published previously (Hellín et al., 2001).

\section{Texture measurement}

Texture values were obtained with a handheld Bertuzzi penetrometer (Effegi, Italy), scale $0-5 \mathrm{~kg} / \mathrm{cm}^{2}$.

\section{Statistical analysis}

The content of FOS and calcium concentration was considered as treatments for osmotic treatment and vacuum infiltration. The effect of the treatment on sugars concentration and texture was determined by one-way ANOVA. LSD's homogeneity means test $(\mathrm{P}<0.05)$ was used. The statistical computer program used was Statistix 8 for Windows (Analytical Software, Tallahassee, FL, USA). All the experiments were made at least in duplicate, the samples analyses in triplicate, and the batch of canned pears was of $n=6$ cans.

\section{RESULTS AND DISCUSSION}

\section{Osmotic treatment}

The Table 1 shows the composition of sugars (mg/100 g) in pears and syrup after two months of storage, for the osmotic treatment, in six different batches. The most important result is the fact that being initially FOS only in the canning syrup, after two months (probably also after one month, but sampling of the different batches was after two months) FOS were in the canned pears (1401 mg/100 g) and in the syrup $(1357 \mathrm{mg} / 100 \mathrm{~g})$. These concentrations of FOS were higher in the batches using natural lemon juice instead of citric acid: pears (2231 mg/100 g) and syrup (2083 mg/100 g). We have no explanation to the differences between batches acidified with citric acid and batches acidified with natural lemon juice, since the acidity of the syrups was rather similar, around $0.2 \% \mathrm{w} / \mathrm{w}$ of anhydrous citric acid, also the amount of added FOS, and all cans were processed and sterilized in the same conditions. The aspect (Fig. 1) of the canned pears in halves enriched in FOS coming from the syrup with citric acid (the so called osmotic treatment), after two months of storage, is the typical of canned pears.

Comparing the concentration of FOS between the initial syrup $(9.1 \% \mathrm{w} / \mathrm{w})$ and the syrup and canned pears (batches 2 and 5) two months after canning (Table 1), the retention of FOS was up to $61 \%$, considering $170 \mathrm{~g}$ of initial syrup and $430 \mathrm{~g}$ of final net weight of the can. There was a missing FOS of 39\%. The FOS must suffer a hydrolysis that produces fructose, starting at the heating of the syrup to $95^{\circ} \mathrm{C}$ (to be added to the can containing the pears) and continuing with the sterilization treatment $\left(95^{\circ} \mathrm{C}\right.$ for $\left.15 \mathrm{~min}\right)$. The hydrolysis should not be very intense in the presence of pears (batches number 2

Table 1: Fructooligosaccharides (FOS), sucrose, glucose, xylose, galactose, fructose, inositol, sorbitol and total sugar concentration $(\mathrm{mg} / 100 \mathrm{~g})$ in canned pears $(P)$ and syrup $(S)$ from the osmotic treatment, after two months of storage at room temperature ( $\mathrm{n}=6 \mathrm{cans} / \mathrm{batch})$

\begin{tabular}{lccccccccc}
\hline Batch & FOS & Sucrose & Glucose & Xylose & Galactose & Fructose & Inositol & Sorbitol & Total sugars \\
\hline 1 P & n.d. & $3046^{\mathrm{a}}$ & $3355^{\mathrm{a}}$ & n.d. & n.d. & $7197^{\mathrm{a}}$ & $131^{\mathrm{a}}$ & $1088^{\mathrm{a}}$ & $14817^{\mathrm{a}}$ \\
1 S & n.d. & $3293^{\mathrm{a}}$ & $3371^{\mathrm{a}}$ & $236^{\mathrm{a}}$ & $404^{\mathrm{a}}$ & $6990^{\mathrm{a}}$ & $49 \mathrm{~b}$ & $1150^{\mathrm{a}}$ & $15493^{\mathrm{a}}$ \\
2 P & $1401^{\mathrm{a}}$ & $2125^{\mathrm{a}}$ & $4382^{\mathrm{a}}$ & n.d. & n.d. & $9211^{\mathrm{a}}$ & $53^{\mathrm{a}}$ & $1027^{\mathrm{a}}$ & $18199^{\mathrm{a}}$ \\
2 S & $1357^{\mathrm{a}}$ & $1978^{\mathrm{a}}$ & $4076^{\mathrm{a}}$ & $361^{\mathrm{a}}$ & n.d. & $8738^{\mathrm{a}}$ & $47^{\mathrm{a}}$ & $1065^{\mathrm{a}}$ & $17622^{\mathrm{a}}$ \\
3 P & - & - & - & - & - & - & - & - & - \\
3 S & 40 & 1644 & 12944 & n.d. & n.d. & 20987 & n.d. & n.d. & 35615 \\
4 P & n.d. & $3564^{\mathrm{a}}$ & $2148^{\mathrm{a}}$ & n.d. & n.d. & $6381^{\mathrm{a}}$ & $110^{\mathrm{a}}$ & $1243^{\mathrm{a}}$ & $13446^{\mathrm{a}}$ \\
4 S & n.d. & $3477^{\mathrm{a}}$ & $2175^{\mathrm{a}}$ & $189^{\mathrm{a}}$ & $354^{\mathrm{a}}$ & $6097^{\mathrm{a}}$ & $30 \mathrm{~b}$ & $1236^{\mathrm{a}}$ & $14351^{\mathrm{a}}$ \\
5 P & $2231^{\mathrm{a}}$ & $3363^{\mathrm{a}}$ & $3050^{\mathrm{ab}}$ & n.d. & n.d. & $7471^{\mathrm{a}}$ & $72^{\mathrm{a}}$ & $1089^{\mathrm{a}}$ & $17276^{\mathrm{a}}$ \\
5 S & $2083^{\mathrm{a}}$ & $3214^{\mathrm{a}}$ & $3029^{\mathrm{a}}$ & $189^{\mathrm{a}}$ & $271^{\mathrm{a}}$ & $7142^{\mathrm{a}}$ & $21^{\mathrm{a}}$ & $1076^{\mathrm{a}}$ & $17025^{\mathrm{a}}$ \\
6 P & - & - & - & - & - & - & - & - & - \\
6 S & 416 & 6191 & 9297 & n.d. & n.d. & 15626 & n.d. & n.d. & 31530 \\
\hline
\end{tabular}

Each can from a batch was separated in the canned pears (P) and the corresponding syrup (S). Batches were as follows 1: No osmotic infiltration of FOS, syrup with citric acid. 2: Osmotic infiltration of FOS, syrup with citric acid. 3: No pears in the cans, only FOS and syrup with citric acid. 4-6 as 1-3 with pasteurized natural lemon juice instead of citric acid.

a,b: different letters within the same column differ significantly $(P<0.05)$

n.d.: not detected. 
and 5), indicating stability of the FOS, although not a stability of $100 \%$ under treatments at temperatures of $90-95^{\circ} \mathrm{C}$ for sterilization. When FOS (Table 1) were put into syrup without pears (batches number 3 and 6) final FOS concentration was lower than when FOS were put into syrup with pears (batches number 2 and 5). This suggests that pears act like a degradation preservative of this complex sugar. However, the $3 \mathrm{~S}$ and $6 \mathrm{~S}$ samples (syrup containing canned FOS without pears), had a value of 40 and $416 \mathrm{mg}$ of FOS in $100 \mathrm{~g}$, respectively, which indicates a strong degradation of the canned FOS during the sterilization in the absence of pears, and fructose and glucose reached the highest concentration in batches without pears. These high concentrations are due to some hydrolysis of FOS and mainly hydrolysis of sucrose into glucose and fructose. L'homme et al. (2003) determined that cooking or pasteurization are not responsible of the fructooligosaccharide loss, and the FOS retention in acidic foods ( $\mathrm{pH}$ 3.5) treated at $95^{\circ} \mathrm{C}$ is higher than $95 \%$ (Vega and Zuniga-Hansen, 2015).

The same happens with sucrose. It has been partially hydrolyzed into glucose and fructose, increasing the amounts of these. It is also necessary to consider the sucrose, glucose and fructose initially provided by the fresh pears. Hudina and Stampar (2000) reported in fresh pears (Pyrus communis L. cv. Williams) the content of sucrose $(445 \mathrm{mg} / 100 \mathrm{~g})$, glucose $(1456 \mathrm{mg} / 100 \mathrm{~g})$, fructose (4463 mg/100 g) and sorbitol (1754 mg/100 g). Considering the content of sucrose of the batches 2 and 5 (Table 1) and the content of sucrose of the fresh pears, then the retention of the sucrose was up to $41 \%$.

Fructose was the sugar which reached the highest concentration in all batches which had pears and syrup (number 1, 2, 4 and 5), between 9211 and $6097 \mathrm{mg} / 100 \mathrm{~g}$. On the contrary, inositol reached the lowest values, between 131 and $21 \mathrm{mg} / 100 \mathrm{~g}$. As it can be observed in Table 1, in two months each sugar reached concentration equilibrium between pears and syrup, except for xylose and galactose. Although pears have xylose and galactose, these sugars were not detected in pears, but they do in syrup. This result suggests that all xylose and galactose come off pears and stay in the syrup, not reaching sugars concentration equilibrium. In spite that xylose and galactose did not reach concentration equilibrium, total sugar concentration did. This result shows that individual sugar concentration equilibrium is not necessary to reach the whole sugar equilibrium.

It is not possible to go further in the discussion of these results with those of other authors, since previously, nobody has done a work similar to this, neither in pears, nor in other canned fruits, although the idea has already been developed in other foods, such as juices (Vidal Fonteles and Rodrigues, 2018), and mainly bakery products such as bread (Korus et al., 2006; Frutos et al., 2008) and cookies (Ayyappan et al., 2015). These last authors indicate a retention of the prebiotic xylooligosaccharides in the cookies relatively high (74\%), and higher that the retention of fructoligosaccharides (61\%) in the canned pears (osmotic treatment). This indicates the effect of a solid or liquid system and baking and sterilization temperatures, respectively, apart from the fact that an oligoxylose is not the same as an oligofructose.

Several authors have studied the osmotic treatment in different fruits (Torreggiani and Bertolo, 2001; Rastogi et al., 2004; Rózek et al., 2010). They determined that the mass transport in osmotic treatment is a combination of simultaneous water and solutes transfer process. Furthermore, the equilibrium distribution of water and solids is influenced by temperature, syrup concentration, porosity of food material, specific surface area of food pieces, among others.

Texture changes in canned pears after two months (batch 1 P: $2.0 \pm 0.1 \mathrm{~kg} / \mathrm{cm}^{2}$ ) of storage presented statistically

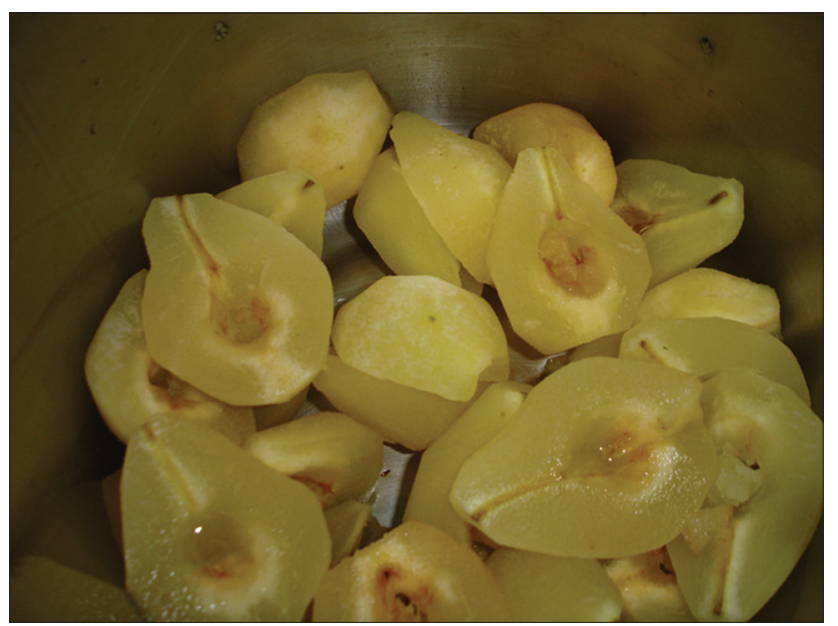

Fig 1. Aspect of the canned pears in halves enriched in FOS by the so called osmotic treatment, with citric acid in the syrup, after two months of storage.

Table 2: Textures $\left(\mathrm{kg} / \mathrm{cm}^{2}\right)$ obtained before and after calcium infiltration and the difference between texture before infiltration and after infiltration $(\Delta \mathrm{T})$

\begin{tabular}{lccc}
\hline $\begin{array}{l}\text { Calcium } \\
\text { concentration }(\mathrm{mg} / \mathrm{l})\end{array}$ & $\begin{array}{c}\text { Texture before } \\
\text { infiltration }\end{array}$ & $\begin{array}{c}\text { Texture after } \\
\text { infiltration }\end{array}$ & $\Delta \mathbf{T}$ \\
\hline 0 & $4.3^{\mathrm{a}}$ & $3.2 \mathrm{~b}$ & $1.1^{\mathrm{a}}$ \\
50 & $4.7^{\mathrm{a}}$ & $4.3^{\mathrm{a}}$ & $0.4^{\mathrm{ab}}$ \\
100 & $4.7^{\mathrm{a}}$ & $4.2^{\mathrm{a}}$ & $0.5^{\mathrm{ab}}$ \\
200 & $5.0^{\mathrm{a}}$ & $5.0^{\mathrm{a}}$ & $0.0^{\mathrm{b}}$ \\
500 & $3.8^{\mathrm{a}}$ & $3.4^{\mathrm{a}}$ & $0.4^{\mathrm{ab}}$ \\
\hline a,ab,b: different letters within the same row differ significantly $(\mathrm{P}<0.05)$. &
\end{tabular}




\begin{tabular}{|c|c|c|c|c|c|c|c|c|c|}
\hline Sample & FOS & Sucrose & Glucose & Xylose & Galactose & Fructose & Inositol & Sorbitol & Total sugars \\
\hline $3 P$ & $128^{a}$ & $4814^{a}$ & $4164^{a}$ & n.d. & n.d. & $5666 \mathrm{a}$ & $119 a$ & $1426 \mathrm{a}$ & $16317 \mathrm{a}$ \\
\hline $3 S$ & $79^{a}$ & $3722^{a}$ & $3016^{a}$ & n.d. & n.d. & $4924 a$ & $38 \mathrm{~b}$ & 1096 a & $12875 a$ \\
\hline $20 \mathrm{P}$ & $140^{\mathrm{a}}$ & $4750^{a}$ & $3943^{a}$ & n.d. & n.d. & $5901 \mathrm{a}$ & $206 a$ & 1505 a & $16445 \mathrm{a}$ \\
\hline $20 \mathrm{~S}$ & $107^{\mathrm{a}}$ & $3685^{a}$ & $3209^{a}$ & n.d. & n.d. & $5169 \mathrm{a}$ & $86 a$ & 1106 a & $13362 \mathrm{a}$ \\
\hline $35 \mathrm{P}$ & $146^{a}$ & $4330^{a}$ & $4067^{a}$ & n.d. & n.d. & $5542 \mathrm{a}$ & $93 a$ & $1552 \mathrm{a}$ & $15730 \mathrm{a}$ \\
\hline $35 \mathrm{~S}$ & $112^{\mathrm{a}}$ & $3608^{a}$ & $2957^{a}$ & n.d. & n.d. & $4865 a$ & $95 a$ & 1104 a & $12741 \mathrm{a}$ \\
\hline $60 P$ & $164^{\mathrm{a}}$ & $4719^{a}$ & $3666^{a}$ & n.d. & n.d. & 5659 a & $203 a$ & 1549 a & $15960 \mathrm{a}$ \\
\hline $60 \mathrm{~S}$ & $109^{a}$ & $3801^{a}$ & $3457^{a}$ & n.d. & n.d. & $5510 a$ & $80 a$ & $1151 \mathrm{a}$ & $14108 a$ \\
\hline
\end{tabular}

Each can at sampling time was separated in the canned pears $(P)$ and the corresponding syrup (S), being the sampling at $3,20,35$, and 60 days. a,b: different letters within the same column differ significantly $(P<0.05)$.

n.d.: not detected.

differences $(\mathrm{P}<0.05)$ with initial texture values of the fresh pears $\left(4.6 \pm 0.3 \mathrm{~kg} / \mathrm{cm}^{2}\right)$. This result indicates that the canning process cause a change in the texture of pears. This softening is due to partial degradation of the pectic polysaccharides of the fruit cell-wall (Bourne and Comstock, 1986; Missang et al., 2011). In general, the industrial processing of fruits and vegetables, with heat or cold treatments, affects their texture (González Hidalgo et al., 2019).

\section{Vacuum impregnation}

As an alternative to osmotic treatment, vacuum impregnation to introduce FOS into pears was tried. After a first vacuum treatment we notice that the texture of the pears has changed quite a lot. The pears were soft and visually they were not appetizing. Vacuum infiltration provokes not only the exchange of internal gas or free liquid in the pores for external liquid, but also changes in the pore volume (Nowacka et al., 2014). Furthermore, the texture quality of vacuum impregnation processes products is significantly related to the type of vacuum impregnation solutions used (Martínez-Monzó et al., 1998), To solve this problem of texture loss in the pears enriched with FOS to be canned, different quantities of calcium were added to the impregnation medium: 0 (control), 50, 100, 200 and $500 \mathrm{mg} / \mathrm{l}$. As the Table 2 shows the only calcium concentration which it was obtained statistically significant differences with the control was $200 \mathrm{mg} / \mathrm{l}$. This was the calcium concentration chosen to be added to the impregnation medium. After vacuum impregnation with $200 \mathrm{mg} / \mathrm{l}$ of calcium concentration, $9.1 \%$ (w/w) of FOS concentration and citric acid, cans were closed and processed. After 3, 20, 35 and 60 days, cans were opened. As Table 3 shows after 3 days of storage, all sugars almost reached composition equilibrium. After 20 days, all sugars reached composition equilibrium.

In pears, final concentration (Table 1) of FOS and fructose after osmotic treatment (2231 and $7471 \mathrm{mg} / 100 \mathrm{~g}$, respectively) was higher than final concentration (Table 3 ) of the same sugars after vacuum impregnation (FOS $164 \mathrm{mg} / 100 \mathrm{~g}$ and fructose $5659 \mathrm{mg} / 100 \mathrm{~g}$ ). This result clearly indicates that the vacuum impregnation as a procedure for introducing the FOS into the pear halves and then canning them results in a very low concentration of FOS in the canned fruit, which is a disadvantage compared to the osmotic treatment, which produces a FOS concentration up to 14 times higher.

On the other hand, sucrose final values (two months) were higher after vacuum impregnation $(4719 \mathrm{mg} / 100 \mathrm{~g})$ than after osmotic treatment $(2125 \mathrm{mg} / 100 \mathrm{~g})$. Final concentrations of glucose and sorbitol did not present significant differences between both treatments. In syrup, final concentration of FOS and fructose after osmotic treatment (1357 and $8738 \mathrm{mg} / 100 \mathrm{~g}$, respectively) was higher than final concentration of the same sugars after vacuum impregnation (FOS $109 \mathrm{mg} / 100 \mathrm{~g}$ and fructose $5510 \mathrm{mg} / 100 \mathrm{~g})$. On the other hand, sucrose final values were higher after vacuum impregnation $(3801 \mathrm{mg} / 100 \mathrm{~g})$ than after osmotic treatment $(1978 \mathrm{mg} / 100 \mathrm{~g})$. Final concentrations of glucose and sorbitol did not present significant differences between both treatments.

It is not possible to go further in the discussion of these results with those of other authors, since previously, nobody has done a work similar to this, neither in pears, nor in other canned fruits, although the idea has already been developed in other foods, as mentioned above for the osmotic treatment.

\section{CONCLUSION}

The two procedures, the osmotic treatment and the vacuum impregnation, can be used to put FOS into pears, being the concentration of FOS in the canned pears and the corresponding syrup up to 14 times higher using the osmotic treatment than the vacuum infiltration. Those FOS (retention of up to 61\%) remain stable after 
processing and during the storage time of the canned pears, in both the pears and the syrup. Thank to this stability it is possible to get prebiotic canned pears (enriched with FOS) with the same sensory properties than canned pears without any prebiotic compound, since FOS do not contribute to the sweetness of the canned pears. These results indicated that canned pears rich in FOS have potential to be a new functional food that can be produced at industrial level.

\section{Authors' contributions}

In this research, J.M.R.G. designed and help to carried out the experiment. M.T.G.B. carried out the treatments of the pears, canning, sampling and basic analyses. I.G.H. performed laboratory analysis of H.P.L.C. and conducted the statistical analyses, with the help of J.M.R.G. Finally, I.G.H. and J.M.R.G. wrote the manuscript which was read and approved by all the authors.

\section{DECLARATION OF CONFLICTING INTERESTS}

The authors declared no potential conflicts of interest with respect to the research, authorship, and/or publication of this article.

\section{FUNDING}

The authors received no financial support for the research, authorship, and/or publication of this article; only the laboratory facilities at Food Technology, University of Murcia.

\section{ORCID ID}

Ros-García José María http:/ / orcid.org/0000-0002-9170899X

\section{REFERENCES}

Ayyappan, P., A. Abirami, N. A. Anbuvahini, P. S. T. Kumaran, M. Naresh, D. Malathi and A. Usha. 2015. Physicochemical properties of cookies enriched with xylooligosaccharides. Food Sci. Technol. Int. 22(5): 420-428.

Betoret, N., L. Puente, M. J. Díaz, M. J. Pagán, M. J. García, M. L. Gras, J. Martínez-Monzó and P. Fito. 2003. Development of probiotic-enriched dried fruits by vacuum impregnation. J. Food Eng. 56(2-3): 273-277.

Bornet, F. R. J., F. Brouns, Y. Tashiro and V. Duvullier. 2002. Nutritional aspects of short-chain fructooligosaccharides: Natural occurrence, chemistry, physiology and health implications. Digest. Liver Dis. 34: 111-120.

Bourne, M. C and S. H. Comstock. 1986. Effect of temperature on firmness of thermally processed fruits and vegetables. J. Food Sci. 51(2): 531-533.
Frutos, M. J., L. Guilabert-Antón, A. Tomás-Bellido and J.A. HernándezHerrero. 2008. Effect of artichoke (Cynara scolymus L.) fiber on textural and sensory qualities of wheat bread. Food Sci. Technol. Int. 14(5): 49-55.

Gibson, G. R. 2004. Fibre and effects on probiotics (the prebiotic concept). Clin. Nutr. Suppl. 1: 25-31.

González-Hidalgo, I., D. A. Moreno, C. García-Viguera and J. M. RosGarcía. 2019. Effect of industrial freezing on the physical and nutritional quality traits in broccoli. Food Sci. Technol. Int. 25(1): 56-65.

Hellín, P., J. M. Ros and J. Laencina. 2001. Changes in high and low molecular weight carbohydrates during Rhizopus nigricans cultivation on lemon peel. Carbohydr. Polym. 45: 169-174.

Hidaka, H., T. Eida, T. Tarizawa, T. Tokunaya and Y. Tashito. 1986. Effects of fructooligosaccharides on intestinal flora and human health. Bifidobacteria Microflora. 5: 37-50.

Hudina, M and F. Stampar. 2000. Free sugar and sorbitol content in pear (Pyrus communis L.) cv. 'Williams' during fruit development using different treatments. ISHS Acta Hortic. 514: 269-274.

Korus, J., K. Grzelak, K. Achremowicz and R. Sabat. 2006. Influence of prebiotic additions on the quality of gluten-free bread and on the content of inulin and fructooligosaccharides. Food Sci. Technol. Int. 12(6): 489-495.

Kumar, C. G., S. Sripada and Y. Poornachandra. 2018. Status and future prospects of fructooligosaccharides as nutraceuticals. In: Grumezescu A. M and A. M. Holban, editors. Role of Materials Science in Food Bioengineering, Academic Press, New York, pp. 451-503.

Li, W., K. Wang, Y. Sun, H. Ye, B. Hu and X. Zeng. 2015. Influences of structures of galactooligosaccharides and fructooligosaccharides on the fermentation in vitro by human intestinal microbiota. J. Funct. Foods. 13: 158-168.

L'homme, C., A. Puigserver and A. Biagini. 2003. Effect of foodprocessing on the degradation of fructooligosaccharides in fruit. Food Chem. 82: 533-537.

Martínez-Monzó, J., N. Martínez-Navarrete, A. Chiralt and P. Fito. 1998. Mechanical and structural changes in apple (Var. Granny Smith) due to vacuum impregnation with cryoprotectants. J. Food Sci. 63(3): 499-503.

McKellar, R. C and H. W. Modler. 1989. Metabolism of fructooligosaccharides by Bifidobacterium Spp. Appl. Microbiol. Biotechnol. 31: 537-541.

Missang, C. E., J. F. Maingonnat, C. M. G. Renard and J. M. Audergon. 2011. Texture variation in apricot: Intra-fruit heterogeneity, impact of thinning and relation with the texture after cooking. Food Res. Int. 44(1): 46-53.

Nobre, C., E. G. F. Alves, F. A. N. Fernandes, E. S. Brito, S. Rodrigues, J. A. Teixeira and L. R. Rodrigues. 2018. Production of fructooligosaccharides by Aspergillus ibericus and their chemical characterization. LWT Food Sci. Technol. 89: 58-64.

Pérez-Cabrera, L., M. Cháfer, A. Chiralt and C. González-Martínez. 2011. Effectiveness of antibrowning agents applied by vacuum impregnation on minimally processed pear. LWT Food Sci. Technol. 44: 2273-2280.

Nowacka, M., U. Tylewicz, L. Laghi, M. R. Dalla and D. WitrowaRajchert. 2014. Effect of ultrasound treatment on the water state in kiwifruit during osmotic dehydration. Food Chem. 144(1): 18-25.

Rastogi, N. K., C. A. Nayak and K. S. M. Raghavarao. 2004. Influence of osmotic pre-treatments on rehydration characteristics of carrots. J. Food Eng. 65(2): 287-292.

Rózek, A., J. V. García-Pérez, F. López, C. Güell and M. Ferrando. 
2010. Infusion of grape phenolics into fruits and vegetables by osmotic treatment: Phenolic stability during air drying. J. Food Eng. 99(2): 142-150.

Sugizaki, C. S. A and M. M. V. Naves. 2018. Potential prebiotic properties of nuts and edible seeds and their relationship to obesity. Nutrients. 10: 1645.

Torreggiani, D and G. Bertolo. 2001. Osmotic pre-treatments in fruit processing: chemical, physical and structural effects. J. Food Eng. 49(2-3): 247-253.
Vega, R and M. E. Zuniga-Hansen. 2015. The effect of processing conditions on the stability of fructooligosaccharides in acidic food products. Food Chem. 173: 784-789.

Vidal, T. F and S. Rodrigues. 2018. Prebiotic in fruit juice: Processing challenges, advances, and perspectives. Curr. Opin. Food Sci. 22: 55-61.

Yanyun, Z., P. Su-il, W. L. Scott and M. G. Traber. 2005. Vitamin E and mineral fortification in fresh-cut apples (Fuji) using vacuum impregnation. Nutr. Food Sci. 35(6): 393-402. 